\title{
Incidence of Ambulatory Care Visits and Association with Comorbidities of Overactive Bladder in Taiwan
}

\author{
Hsin-Li Liu ${ }^{1}$, Kai-Yu Tseng ${ }^{1}$, Shu-Ching Chiu ${ }^{1}$, Horng-Mo Lee ${ }^{2}$, Yueh-Chin Chung,"* \\ ${ }^{1}$ Department of Nursing, Central Taiwan University of Science and Technology, Taichung, Taiwan \\ ${ }^{2}$ School of Medical Laboratory Sciences and Biotechnology, Taipei Medical University, Taipei, Taiwan \\ *Corresponding Author: Yueh-Chin Chung, Ph.D. Department of Nursing, Central Taiwan University \\ of Science and Technology, Taichung, Taiwan, No.666, Buzih Road, Beitun District, Taichung City 40601, \\ Taiwan.Email: ycchung@ctust.edu.tw
}

\begin{abstract}
Objectives: The present study is designed to explore the incidence of ambulatory care visits and association with comorbidities of overactive bladder $(O A B)$ in Taiwan.

Methods: Data from the National Health Insurance Research Database(LHID) 2005 containing all of the original claim data of 1,000,000 beneficiaries enrolled in 2005 were randomly sampled from the 2005 Registry for Beneficiaries (ID) of the NHIRD and then statistically analyzed in terms of percentage, incidence of ambulatory care visits, odds ratio (OR), and $95 \%$ confidence intervals.

Results: The subjects enrolled in this study included females (62.93\%) mostly aged 51 to 60 years (19.97\%) and males (19.68\%) aged 71 to 80 years. The ratio of females to males was 0.8-2.51:1.0. Overall, the annual incidence of ambulatory care visits increased from $2.1 \%$ in 2006 to $2.9 \%$ in 2009. The annual incidence of ambulatory care visits of females and males reached the maximum of $3.5 \%$ and $2.3 \%$ in 2009. In females, comorbidities, such as frequent urination, urinary incontinence (UI), and urinary calculi, and menopause $(O R>1 ; P<0.05)$. In males, frequent urination, nocturnal enuresis, UI, benign prostatic hypertrophy and anxiety state $(O R>1 ; P<0.05)$ were associated with $O A B$.
\end{abstract}

Conclusions: The incidence of ambulatory care visits of patients with OAB in Taiwan was low. OAB may significantly affect the quality of life. Thus, the medical attention and effective treatment for patients with $O A B$ should be enhanced.

Abbreviations: OAB: overactive bladder, UI: urinary incontinence, UUI: urge urinary incontinence, SUI: stress urinary incontinence, LUTS: lower urinary tract symptoms, ICD: international classification of diseases, NHIRD: National Health Insurance Research Database, OR:odds ratio.

Keywords: overactive bladder; incidence; ambulatory carevisits; comorbidities; National Health Insurance Research Database.

\section{INTRODUCTION}

Overactive bladder $(\mathrm{OAB})$, a common but easily neglected condition accompanied with bladder hypersensitivity or contraction abnormalities and often resulting in urgent urination, frequent urination, nocturnal enuresis, or urinary incontinence (UI), causes embarrassment and may interfere with normal life[1]. Wein and Rovner emphasized that $\mathrm{OAB}$ covers a very wide range, including urge urinary incontinence (UUI), a portion of mixed UI, a portion of stress urinary incontinence (SUI)[2], and a sense of urgency in urine, which is the main symptom of $\mathrm{OAB}[3]$.
The prevalence of $\mathrm{OAB}$ also increases with age, that is, $12 \%$ to $22 \%$ of affected individuals are over 40 years old and $30 \%$ to $40 \%$ of such individuals are over 75 years old; one-third of these patients present signs of UI[4]. Stewart, Herzog, and We in reported that 21 million people in the United States experience urinary frequency and urinary urgency but not UI, and 3.3 billion patients manifest $\mathrm{OAB}[5]$. The attack rate of $\mathrm{OAB}$ may increase with age, and $60 \%$ showed symptoms, but only $27 \%$ received treatment. The prevalence of $\mathrm{OAB}$ may also increase with age and may affect $5.9 \%$ to $16 \%$ of males and $6.0 \%$ to $16.9 \%$ of females [6]. 
Moorthy, Lapitan, Quek, and Lim surveyed 2,369 male patients with a mean age of 18 to 70 years in 11 Asian countries in 1998 and found that 709 patients $(29.9 \%)$ suffered from OAB, and $43.0 \%$ of these patients were at the working age; the incidence of $\mathrm{OAB}$ increased with age, and the age group of over 70 years accounted for 53.0\%[7]. Abrams et al. indicated that females present a higher risks of $\mathrm{OAB}$ than males [8].

About $10 \%$ to $18 \%$ of the Taiwanese population showed varying degrees of $\mathrm{OAB}$, and the prevalence rate increases with age. Among 23 million Taiwanese, approximately 4.14 million people are at a serious risk of $\mathrm{OAB}$, but only $13 \%$ of these individuals have sought medical attention [9]. The prevalence of OAB among females aged over 20 years in Taiwan is $36.0 \%$ [10]. Irwin et al. estimated that 0.303 billion females aged more than 20 years will experience UI, 0.255 billion females will suffer from stress incontinence, 53 million females will complain of mixed incontinence, and 33 million of females will manifest UI by 2018; approximately 0.298 billion individuals will suffer from OAB[11]. The prevalence of UI among females is greater than that among males, and their medians correspond to 27.6$58.4 \%$ and $10.5 \%[12,13]$.

The risk factors of $\mathrm{OAB}$ in females include urinary tract infection, SUI, interstitial cystitis, menopause, polyuria, diabetes, heart failure, medication, and aging $(\mathrm{P}<0.05)[14,15]$. The risk factors of $\mathrm{OAB}$ for males are aging, constipation, and prostate enlargement $(\mathrm{P}<0.05)[16,17]$. Surgical treatments, cystic calculus, obesity, and neurological abnormalities, such as stroke, Parkinson's disease, anxiety, and lower urinary tract symptoms (LUTS), are also factors contributing to $\mathrm{OAB}[18]$. The prevalence of LUTS is $41 \%$, which increases with age; for the age groups of 18 to 49,50 to 64 , and $\geq 65$ years, the prevalence rates correspond to $14.1 \%, 41.5 \%$, and $60.8 \%[19]$, and SUI accounts for about $50 \%[20,21]$.

With regard to the effects of $\mathrm{OAB}$ on living quality, the survey results in the 11 Asian countries showed that $53 \%$ of Asian women have developed symptoms of $\mathrm{OAB}$, but only $21 \%$ of these women have sought medical attention. The 2014 survey in Taiwan also revealed that $35 \%$ of Taiwanese women were aware of their $\mathrm{OAB}$ symptoms. OAB symptoms often negatively affect the social life, work, mood, family life, and sex life of patients and thus seriously affect their quality of life $[18,19$, 22-30].

With the effects of $\mathrm{OAB}$ symptoms on their careers, the daily work of $24.9 \%$ of male patients is affected and job decisions for $10 \%$ of male patients are underdetermined and thus prompt them to change jobs or become dismissed; early retirement is documented in $7.8 \%$ of male patients; female patients also experience similar cases [6,28].

$\mathrm{OAB}$ affecting the quality of life in the healthcare system has been extensively investigated. Therefore, this study examined the annual incidence of ambulatory care visits, gender ratio, and comorbidity of OAB by using the relevant data from the National Health Insurance Research Database of Taiwan from 2003 to 2010 and by providing research data regarding the current condition of $\mathrm{OAB}$ in Taiwan and other factors to predict its future condition.

\section{Materials And MethodS}

\subsection{Data Collection}

This paper presents a longitudinal study with data sourced from the relevant outpatient and medical insurance files of LHID 2005. The LHID 2005 contains all the original claim data of 1,000,000 beneficiaries enrolled in 2005 and randomly sampled from the 2005 Registry for Beneficiaries (ID) of the National Health Insurance Research Database (NHIRD), which was released once every 40,000 beneficiaries were sampled and then updated once a year. In this study, the column (ACODE_ICD9_1) of the international classification of diseases(ICD) in the outpatient files (CD) of the National Health Insurance Research Database is cited, with the first three codes in front of the ICD representing the current diagnosis of a subject investigated, thereby obtaining the primary diagnostic distribution and dividing the diagnosis districts into 18 groups.

The present study included 503 males and 854 females, comprising a total of 1,357 subjects. The patients enrolled were diagnosed of $\mathrm{OAB}$ from 2003 to 2010 (ICD-9-CM: 596.51 patients). The diagnostic codes of comorbidities are as follows: diabetes mellitus (250), multiple sclerosis (MS) (340), secondary parkinsonism (332.1), renal calculus (592), ureteral calculus 
(592.1), acute cystitis (595), frequent urination (788.41), nocturnal enuresis (788.43), UI (788.31), other urination abnormalities (788.69), benign prostatic hypertrophy (BPH) (600), menopause $(627.2,627.8,627.9)$, and anxiety state $(300.00,300.02,300.09)$. This study was approved by the NHRI Review Committee and by the Institutional Review Board of the China Medical University Hospital, Taichung, Taiwan (CMUH103-REC1-088).

\subsection{Statistical Analysis}

SPSS17.0 statistical software was used for data reduction and subsequent analysis. The age/sex distribution of 2003 to $2010 \mathrm{OAB}$ patients was analyzed in terms of percentage. The annual consultation rate was calculated on the basis of gender to provide data of the current situation of $\mathrm{OAB}$ in Taiwan. The presence of $\mathrm{OAB}$ comorbidity in different genders is quantified by odds ratio (OR). Accordingly, 95\% confidence interval was used for correlation and significance. The significance level $(\alpha)$ was set to 0.05 .

\section{RESUlts}

In this study, 503 males and 854 females, comprising a total of 1,357 cases, were enrolled. After the age/ gender grouping, 918 cases were found to present hereditary $\mathrm{OAB}$, and the control group was composed of 1,827 subjects. The subjects enrolled were mostly at the age of 51 to 60 years old $(19.97 \%)$. Among these subjects, females accounted for $62.93 \%$, and most of them are at the age of 51 to 60 years old $(20.96 \%)$; majority of males are at the age of 71 to 80 years old $(19.68 \%)$. The gender ratio of females to males was $0.8-2.51: 1.0$, and this ratio varies with age. Differences were found between the genders, particularly in the age groups of 21 to 30,31 to 40,41 to 50,51 to 60 , and 61 to 70 years old $(\mathrm{P}<0.0001)$ (Table 1$)$.

As shown in Table 2, the overall annual incidence of ambulatory care visits increased from $2.1 \%$ in 2006 to $2.9 \%$ in 2009; the annual incidence of ambulatory care visits of females reached the maximum by up to $3.5 \%$ at most in 2009 , whereas that of males reached the peak at $2.3 \%$ in 2009; differences were found in terms of gender in the annual incidence of ambulatory care visits in 2004, 2005, 2008, 2009 and 2010 $(\mathrm{P}<0.0001)$.

Table1. Average sex-specific percentage of overactive bladder, 2003-2010

\begin{tabular}{|l|l|l|l|l|l|l|}
\hline \multirow{2}{*}{ Age } & \multicolumn{3}{|c|}{ Overactive bladder } & Female/male ratio & \multicolumn{1}{|c|}{ OR (95\% CI) } & \multicolumn{1}{|c|}{ P value } \\
\cline { 2 - 4 } & \multicolumn{1}{|c|}{ Female } & \multicolumn{1}{|c|}{ Male } & \multicolumn{1}{|c|}{ Total } & & & \\
\hline 110 & $4(0.47)$ & $5(0.99)$ & $9(0.66)$ & $0.8: 1$ & $0.79(0.21$ to 3.04$)$ & 0.7335 \\
\hline $11-20$ & $16(1.87)$ & $14(2.78)$ & $30(2.21)$ & $1.14: 1$ & $1.17(0.54$ to 2.55$)$ & 0.6922 \\
\hline $21-30$ & $96(11.24)$ & $48(5.42)$ & $144(10.61)$ & $2: 1$ & $26.00(8.88$ to 76.13$)$ & $<0.0001$ \\
\hline $31-40$ & $90(10.54)$ & $59(11.73)$ & $149(10.98)$ & $1.53: 1$ & $6.25(2.91$ to 13.44$)$ & $<0.0001$ \\
\hline $41-50$ & $171(20.02)$ & $68(13.52)$ & $239(17.61)$ & $2.51: 1$ & $2.83(2.10$ to 3.80$)$ & $<0.0001$ \\
\hline $51-60$ & $179(20.96)$ & $92(18.29)$ & $271(19.97)$ & $1.95: 1$ & $2.151(1.65$ to 2.81$)$ & $<0.0001$ \\
\hline $61-70$ & $141(16.51)$ & $78(15.51)$ & $219(16.14)$ & $1.81: 1$ & $1.94(1.45$ to 2.60$)$ & $<0.0001$ \\
\hline $71-80$ & $118(13.82)$ & $99(19.68)$ & $217(15.99)$ & $1.19: 1$ & $1.23(0.92$ to 1.62$)$ & 0.1724 \\
\hline $81-90$ & $41(4.80)$ & $38(7.55)$ & $79(5.82)$ & $1.08: 1$ & $1.13(0.65$ to 1.99$)$ & 0.6644 \\
\hline Total & $854(62.93)$ & $503(37.07)$ & $1357(100.00)$ & $1.70: 1$ & $5.78(4.67$ to 7.17$)$ & $<0.0001$ \\
\hline
\end{tabular}

$O R=$ odds ratio, $C I=$ confidence interval

Table2. Annual incidence $e^{I}$ of overactive bladder, 2003-2010

\begin{tabular}{|l|l|l|l|l|l|l|}
\hline \multicolumn{1}{|c|}{ Year } & \multicolumn{1}{|c|}{ Female } & \multicolumn{1}{c|}{ Male } & \multicolumn{1}{|c|}{ Total } & Female/male ratio & OR (95\% CI) & $P$ value \\
\hline 2003 & $14(0.3)$ & $3(0.1)$ & $17(0.2)$ & $4.67: 1$ & $5.27(1.46$ to 18.94$)$ & 0.0110 \\
\hline 2004 & $54(1.2)$ & $16(0.3)$ & $70(0.7)$ & $3.37: 1$ & $6.16(3.18$ to 11.97$)$ & $<0.0001$ \\
\hline 2005 & $91(2.0)$ & $46(1.0)$ & $137(1.5)$ & $1.98: 1$ & $11.87(5.39$ to 26.15$)$ & $<0.0001$ \\
\hline 2006 & $99(2.2)$ & $96(2.0)$ & $195(2.1)$ & $1.03: 1$ & $4.13(0.45$ to 37.57$)$ & 0.2087 \\
\hline 2007 & $131(2.8)$ & $79(1.7)$ & $210(2.2)$ & $1.66: 1$ & $1.76(1.31$ to 2.36$)$ & 0.0002 \\
\hline 2008 & $146(3.2)$ & $72(1.5)$ & $218(2.3)$ & $2.03: 1$ & $2.20(1.64$ to 2.97$)$ & $<0.0001$ \\
\hline 2009 & $163(3.5)$ & $107(2.3)$ & $270(2.9)$ & $1.52: 1$ & $1.81(1.40$ to 2.35$)$ & $<0.0001$ \\
\hline 2010 & $156(3.4)$ & $84(1.8)$ & $240(2.6)$ & $1.86: 1$ & $2.02(1.52$ to 2.67$)$ & $<0.0001$ \\
\hline Total & $854(2.3)$ & $503(1.3)$ & $1357(1.8)$ & $1.70: 1$ & $5.78(4.66$ to 7.17$)$ & $<0.0001$ \\
\hline
\end{tabular}

OR = odds ratio, $C I=$ confidence interval. 
Incidence of Ambulatory Care Visits and Association with Comorbidities of Overactive Bladder in Taiwan

Annual incidence (per 100 peoplelyear) is the number of new cases of overactive bladder in patients divided by the size of the population at risk each year.

Table3. Comparison of overactive-bladder-related comorbidities in males versus females

\begin{tabular}{|c|c|c|c|c|c|c|c|c|c|}
\hline \multirow[t]{3}{*}{ Disease } & \multirow{3}{*}{\begin{tabular}{|c|} 
ICD-9 \\
code
\end{tabular}} & \multicolumn{2}{|c|}{ Female } & \multirow{3}{*}{$\begin{array}{c}\text { OR } \\
(95 \% \mathrm{CI})\end{array}$} & \multirow[t]{3}{*}{ Pvalue } & \multicolumn{2}{|c|}{ Male } & \multirow{3}{*}{$\begin{array}{c}\text { OR } \\
(95 \% \mathrm{CI})\end{array}$} & \multirow[t]{3}{*}{ P value } \\
\hline & & $\begin{array}{l}\text { Control } \\
\text { group }\end{array}$ & $\begin{array}{c}\text { Compar } \\
\text { ison } \\
\text { group }\end{array}$ & & & \begin{tabular}{|c|} 
Control \\
group
\end{tabular} & $\begin{array}{c}\text { Compa } \\
\text { rison } \\
\text { group }\end{array}$ & & \\
\hline & & $\mathbf{N}$ & $\mathbf{N}$ & & & $\mathbf{N}$ & $\mathbf{N}$ & & \\
\hline $\begin{array}{l}\text { Type2 } \\
\text { diabetes } \\
\text { mellitus }\end{array}$ & 250 & 24 & 254 & $\begin{array}{l}0.07(0.05 \text { to } \\
0.11)\end{array}$ & $<0.0001$ & 15 & 274 & $\begin{array}{l}0.04 \\
(0.02 \text { to } 0.07)\end{array}$ & $<0.0001$ \\
\hline $\begin{array}{l}\text { Multiple } \\
\text { sclerosis }\end{array}$ & 340 & 1 & 8 & $\begin{array}{l}0.12(0.01 \text { to } \\
0.95)\end{array}$ & 0.0443 & 0 & 9 & $\begin{array}{l}0.05 \\
(0.03 \text { to } 0.84)\end{array}$ & 0.0372 \\
\hline $\begin{array}{l}\text { Secondary } \\
\text { parkinsonism }\end{array}$ & 332.1 & 2 & 12 & $\begin{array}{l}0.15(0.03 \text { to } \\
0.69)\end{array}$ & 0.0146 & 0 & 11 & $\begin{array}{l}0.04 \\
(0.00 \text { to } 0.67)\end{array}$ & 0.0251 \\
\hline $\begin{array}{l}\text { Calculus of } \\
\text { kidney }\end{array}$ & 592 & 33 & 19 & $\begin{array}{l}2.10(1.10 \text { to } \\
4.02)\end{array}$ & 0.0060 & 19 & 203 & $\begin{array}{l}0.74 \\
(0.59 \text { to } 0.93)\end{array}$ & 0.0108 \\
\hline $\begin{array}{l}\text { Calculus of } \\
\text { ureter }\end{array}$ & 592.1 & 11 & 8 & $\begin{array}{l}0.65(0.28 \text { to } \\
1.48)\end{array}$ & 0.3033 & 6 & 55 & $\begin{array}{l}0.05 \\
(0.03 \text { to } 013)\end{array}$ & $<0.0001$ \\
\hline Acute cystitis & 595 & 135 & 95 & $\begin{array}{l}1.49 \text { (1.13 to } \\
1.96)\end{array}$ & 0.0053 & 7 & 99 & $\begin{array}{l}0.00 \\
(0.00 \text { to } 0.01)\end{array}$ & $<0.0001$ \\
\hline $\begin{array}{l}\text { Urinary } \\
\text { frequency }\end{array}$ & 788.41 & 122 & 92 & $\begin{array}{l}1.37 \text { (1.03 to } \\
1.83)\end{array}$ & 0.0305 & 51 & 26 & $\begin{array}{l}2.96 \\
(1.63 \text { to } 5.37)\end{array}$ & 0.0003 \\
\hline Nocturia & 788.43 & 23 & 13 & $\begin{array}{l}1.99(0.95 \text { to } \\
4.22)\end{array}$ & 0.0688 & 20 & 6 & $\begin{array}{l}3.92 \\
(1.50 \text { to } 10.23)\end{array}$ & 0.0053 \\
\hline $\begin{array}{l}\text { Urge } \\
\text { incontinence }\end{array}$ & 788.31 & 50 & 25 & $\begin{array}{l}3.00(1.65 \text { to } \\
5.46)\end{array}$ & 0.0003 & 41 & 4 & $\begin{array}{l}1.53 \\
(1.19 \text { to } 1.98)\end{array}$ & 0.0001 \\
\hline $\begin{array}{l}\text { Hesitancy of } \\
\text { micturition }\end{array}$ & 788.69 & 0 & 2 & $\begin{array}{l}0.19(0.01 \text { to } \\
4.14)\end{array}$ & 0.2949 & 0 & 1 & $\begin{array}{l}0.33 \\
(0.01 \text { to } 8.19)\end{array}$ & 0.4988 \\
\hline $\begin{array}{l}\text { Hypertrophy } \\
\text { (benign) of } \\
\text { prostate }\end{array}$ & 600 & & & - & - & 234 & 1 & $\begin{array}{l}612.19(38.12 \text { to } \\
9832.32)\end{array}$ & $<0.0001$ \\
\hline $\begin{array}{l}\text { Menopausal } \\
\text { or female } \\
\text { climacteric } \\
\text { states }\end{array}$ & $\begin{array}{l}627.2 \\
627.8 \\
627.9\end{array}$ & 48 & 10 & $\begin{array}{l}8.31(3.87 \text { to } \\
17.80)\end{array}$ & $<0.0001$ & & & - & - \\
\hline $\begin{array}{l}\text { Anxiety state, } \\
\text { unspecified }\end{array}$ & $\begin{array}{l}30000, \\
30002, \\
30009\end{array}$ & 29 & 399 & $\begin{array}{l}0.05(0.03 \text { to } \\
0.07)\end{array}$ & $<0.0001$ & 15 & 1 & $\begin{array}{l}17.47 \\
(2.26 \\
135.02)\end{array}$ & 0.0061 \\
\hline & & 501 & 937 & & & 417 & 890 & & \\
\hline
\end{tabular}

OR = odds ratio, $C I=$ confidence interval; Ninth revision of the ICD-9-CM (The International Classification of Diseases, Clinical Modification) was used to code and classify morbidity data from outpatient records.

Overactive bladder of Female Denominator (Number of occurrences):501; Male Denominator (Number of occurrences): 417

Non: Overactive bladder of Female Denominator (Number of occurrences): 937; Male Denominator (Number of occurrences): 890 
ARC Journal of Urology

Volume 2, Issue 4, 2017, PP 1-7

ISSN No. (Online):2456-060X

http://dx.doi.org/10.20431/2456-060X.0204001

www.arcjournals.org

After the age/sex grouping, 918 hereditary OAB cases and 1,827 non-hereditary $\mathrm{OAB}$ cases were included for analysis. In terms of the comorbidity of $\mathrm{OAB}$, the OAB-related comorbidities among females included renal calculus, acute cystitis, frequent urination, UI, and menopause $(\mathrm{OR}>1 ; \mathrm{P}<0.05)$, whereas those among males involved frequent urination, nocturnal enuresis, UI, BPH, and anxiety state $(\mathrm{OR}>1 ; \mathrm{P}<0.006)$. Up to 48 females with hereditary $\mathrm{OAB}$ showed menopausal symptoms, and 10 females with non-hereditary $\mathrm{OAB}$ presented menopausal symptoms. The risks for females with hereditary OAB complications and menopausal symptoms were 8.31 times as those of the normal group (95\% CI 3.87-17.80); 50 females with hereditary OAB showed UI symptoms, whereas 25 cases with nonhereditary OAB presented such symptoms. The risks for females with hereditary $\mathrm{OAB}$ complications and UI were thrice as those of the normal group (95\% CI 1.65-5.46); 33 females with hereditary $\mathrm{OAB}$ exhibited renal calculus, and 19 females with non-hereditary OAB displayed renal calculus. The risks for females with hereditary $\mathrm{OAB}$ complications and renal calculus were 2.10 times as those of the normal control group (95\% CI 1.10 -4.02). Up to 234 males with hereditary $\mathrm{OAB}$ presented $\mathrm{BPH}$ symptoms, whereas only one male with nonhereditary $\mathrm{OAB}$ demonstrated such symptoms. The risks for males with hereditary $\mathrm{OAB}$ complications and BPH symptoms were 612.19 times as those of the normal control group (95\% CI 38.12-9832.32); 15 males with hereditary $\mathrm{OAB}$ were in anxiety state, whereas only one male with non-hereditary $\mathrm{OAB}$ was in the same state. The risks for males with hereditary $\mathrm{OAB}$ complications and remaining in anxiety state were 17.47 times as those of the normal group (95\% CI 2.27-135.02). Twenty males with hereditary $\mathrm{OAB}$ presented nocturnal enuresis symptoms, and only six males with nonhereditary $\mathrm{OAB}$ showed such symptoms. The risks for males with hereditary $\mathrm{OAB}$ complications and nocturnal enuresis symptoms were 3.92 times as those of the normal control group (95\% CI 1.50-10.23) (Table 3).

\section{DISCUSSION}

The present study is the first to explore the consultation rate of $\mathrm{OAB}$ in Taiwan on the basis of massive nationwide data. This study, which is characterized by large sample size and massive medical data, is relatively objective, and this study covers the deficiencies of previous studies in terms of various factors, including follow-up, response rate, or recall bias.

The subjects investigated were mainly at the age of 51 to 60 years old $(19.97 \%)$. Females with $\mathrm{OAB}$ were mostly at the age of 51 to 60 years old $(20.96 \%)$, whereas males with such diseases were at the age of 71 to 80 years old $(19.68 \%)$. These findings indicate that the incidence of OAB may increase with age [13].

The results showed that more females suffer from $\mathrm{OAB}$; in terms of $\mathrm{OAB}$ incidence, the ratio of females to males is $0.8-2.51: 1.0$; at the age of 21 to 70 years old, females are in the majority with greater risks for developing $\mathrm{OAB}$ than males[8]. Overall, the annual incidence of ambulatory care visits among all the subjects increased from $2.1 \%$ to $2.9 \%$ in 2006 ; the annual incidence of ambulatory care visits of females was $3.5 \%$ at most, whereas that of males was $2.3 \%$; differences were found between genders in the annual incidence of ambulatory care visits in 2004, 2005, and 2008 up to $2010(\mathrm{p}<0.0001)$; the average incidence of ambulatory care visits of females was $2.3 \%$, which was higher than that of males $(1.3 \%)$. About $10 \%$ to $18 \%$ of the Taiwanese population suffer from $\mathrm{OAB}$; in particular, the prevalence of $\mathrm{OAB}$ among females over 20 years old was up to $36.0 \%$ [10], but only $13 \%$ of them have ever sought for medical attention[6]. As relevant survey results showed, compared with other countries, $60 \%$ of the European population suffer from OAB symptoms, and only $27 \%$ of them have received treatment[5]. The incidence of $\mathrm{OAB}$ among females in Switzerland was $20 \%$, and the cure rate was $42 \%[11]$. The results showed that the incidence of ambulatory care visits of $\mathrm{OAB}$ in Taiwan was low on the basis of the sampling results of the NHIRD because (1) the Orientals are more conservative, and they often think that urinary tract disease is a disease to be ashamed of; thus, they are unwilling to seek medical attention; and (2) many people consider that urinary incontinence is a sign of normal aging, without the need of seeing a 
doctor, thus delaying the optimal time for treatment and seriously affecting the quality of life[29]. The prevalence of LUTS was $41 \%$, which may increase with age[19], and SUI approximately accounted for $50 \%$ of this prevalence[20,21].

OAB comorbidities among females include frequent urination. Milson et al. (2001) reported that the attack rate of $\mathrm{OAB}$ is $16.6 \%$, and $85 \%$ of $\mathrm{OAB}$ patients develop frequent urination; the attack rate increases with age, in which $60 \%$ presented symptoms, but only $27 \%$ received treatment. The risks for females with hereditary OAB complications developing UI are 3.00 times as the normal control group, and the prevalence of UI among females varies significantly from $4.8 \%$ to $58.4 \%$. The prevalence of UI roughly increases with age, and the most common symptom of UI is SUI, approximately accounting for $50 \%$ [2, 13]. The study on Swedish females from 1991 to 2007, the incidence of UI was $21 \%$, and the cure rate was $34 \%$; although the cure rate was not low, $66 \%$ of the females have suffered from UI in the 16 years. The risks for females with hereditary $\mathrm{OAB}$ developing menopause and those for females with $\mathrm{OAB}$ complications suffering from menopausal symptoms were generally 8.31 times as those of the normal control group because post-menopausal females easily leak urine as a result of reduced secretion of female hormones and urethral mucosal atrophy [15].

The risks for males with OAB hereditary complications developing nocturnal enuresis symptoms were generally 3.92 times as those of the normal control group. In epidemiological studies on LUTS, such as those on UI, about $41 \%$ to $62 \%$ of males suffered from LUTS, the incidence among adults over 60 years old increased up to $60.8 \%$ to $81 \%[19,29]$, and SUI approximately accounted for 50\%[20]. LUTS such as frequent urination, nocturnal enuresis, urgent urination, UI, difficulty in urination, intermittent urination, and acute urinary retention are all typical benign BPH symptoms. The risks for males with hereditary $\mathrm{OAB}$ complications and BPH symptoms are generally 612.18 times as those of the normal control group. LUTS and BPH symptoms are also important contributory factors to $\mathrm{OAB}$, negatively affecting sleep quality and mental health[18,19,27,30]. The risks for males with hereditary $\mathrm{OAB}$ complications and remaining in an anxiety state were generally 17.47 times as those of the normal control group. Milsom[6,18] found in his studies on the effects of $\mathrm{OAB}$ on patients' personal development in marketplace that $2 \%$ or $3 \%$ of $\mathrm{OAB}$ patients are in anxiety state, and they often worry about accidents sometimes happening in the rush.

However, certain limitations affect this study. For example, additional physiological data are impossible to access as evidence from NHIRD. As such, only ICD9-CM can be used to distinguish diseases. If patients are unaware that such symptoms are curable or they fail to seek medical treatment, they are slipping through the present study. In addition, the coverage of NHIRD is very limited in terms of education, lifestyle, or social support. Therefore, data collection in the form of questionnaire or qualitative survey is recommended in the future to completely control the effects of other factors.

In Conclusion, a systemic review on the relevant literature worldwide indicated that $\mathrm{OAB}$ may significantly affect work and life quality and increase healthcare spending, and the healthcare spending on $\mathrm{OAB}$ patients may increase with age. The statistics of the consultation rate in the present study are relatively low. The literature verified that the prevalence of $\mathrm{OAB}$ is far above the actual consultation rate. Thus, the consultation and effective curative rates should be improved.

\section{ACKNOWLEDGEMENTS}

This study was supported by a grant from the Central Taiwan University of Science and Technology (CTU105-PC-008).

\section{REFERENCES}

[1] Wein AJ, Rovner ES.Definition and epidemiology of overactive bladder. Urology 2002;60:7-12.

[2] Abrams P, Hanno P, Wein A.Overactive bladder and painful bladder syndrome:There need not be confusion. Neurourol Urodyn 2005; 24:149-150.

[3] Hung M J, Ho ES, Shen PS,et al. Urgency is the core symptom of female overactive bladder syndrome, as demonstrated by a statistical analysis. J Urol 2006; 176:636-640. The Gallup group in collaboration with pharmacia \& Upjohn. Data on file, 1998.

[4] Stewart W, Herzog R, Wein AL.On behalf of the NOBLE program research team: Prevalence and impact of overactive bladder in the US: Results from the NOBLE program. Neurourol Urodyn 2001; 20: 24.

[5] Milson I, Abrams P, Cardozo L, Roberts RG, Thuroff J, Wein AJ. How widespread are the 
symptoms of an overactive bladder and how they are managed? A Population-based prevalence study. British Journal of Urology 2001; 87: 760-766.

[6] Moorthy P, Lapitan MC, Quek PL, Lim PH. Prevalence of overactive bladder in Asian men: An epidemiological survey. British Journal of Urology 2004; 93:528-531.

[7] Abrams P, Kelleher CJ, Kerr LA, Rogers, RG. Overactive bladder significantly affects quality of life. American Journal of Managed Care 2000; 6: S580-590.

[8] Li Weijia, Zhuang Yaoji.Talking about overactive bladder, Chang Gung Medical News 2016; 37:1.

[9] Chen GD, Lin TL, Hu SW, Chen YC, Lin LY. Prevalence and correlation of urinary incontinence and overactive bladder in Taiwanese women. Neurourology \&Urodynamics 2003; 22:109-117.

[10] Irwin DE, Kopp ZS, Agatep B, Milsom I, Abrams P. Worldwide prevalence estimates of lower urinary tract symptoms, overactive bladder, urinary incontinence and bladder outlet obstruction. BJU Int 2011; 108:1132-1138.

[11] Minassian VA, Drutz HP, A1-Badr A.Urinary incontinence as a worldwide problem. Int $\mathbf{J}$ Gynaecol Obstet 2003; 82:327-338.

[12] Smith AL, Wein AJ.Contemporary management of overactive bladder. Postgrad Med 2012; 124:104-116.

[13] Neymark AI, Voytenko AN, Bondarenko AV, Muzalevskaya NI, Kruglykhin IV. DIAGNOSIS AND TREATMENT OF OVERACTIVE BLADDER SYNDROME IN PELVIC INJURIES.Urologiia 2015; 5:38-42.

[14] Wen-Tsang Hsu. Prevalence of Lower Urinary Tract Symptoms and Urinary Incontinence inWomen of the Matsu area of Taiwan. An unpublished Thesis, Institute of Clinical Medicine of National Taiwan University, Taipei. 2006.

[15] Wu JW, Xing YR, Wen YB, et al. Prevalence of Spina Bifida Occulta and Its Relationship With Overactive Bladder in Middle-Aged and Elderly Chinese People. Int Neurourol J 2016; 20:151-158.

[16] Eapen RS, Radomski SB, Review of the epidemiology of overactive bladder Res Rep Urol 2016; 8:71-76.

[17] Golabek T, Skalski M, Przydacz M, et al. Lower urinary tract symptoms, nocturia and overactive bladder in patients with depression and anxiety. Psychiatr Pol 2016; 50:417-30.
[18] Cambronero Santos J, Errando Smet C.Prevalence of storage lower urinary tract symptoms in male patients attending Spanish urology office. Urinary urgency as predictor of quality of life. Actas Urol Esp 2016; Jun 23. pii: S0210-4806(16)30056-0.

[19] Minassian VA, Drutz HP,A1-Badr A.Urinary incontinence as a worldwide problem. Int $\mathbf{J}$ Gynaecol Obstet 2003; 82:327-338.

[20] Smith AL, Wein AJ.Contemporary management of overactive bladder. Postgrad Med 2012; 124:104-116.

[21] Mao-Rong Sun. 2016. Overactive Bladder (OAB). [Cited August 21, 2016].Available from

http://www.cch.org.tw/cchhec/knowledge_detai 1.aspx?oid=113.

[22] Choi H, Bae JH. Overview of the Epidemiology of Lower Urinary Tract Dysfunction in South Korea. Int Neurourol J 2016; 20:91-100.

[23] White N, Iglesia CB.Overactive Bladder. Obstet Gynecol Clin North Am 2016; 4 3:5968.

[24] Reynolds WS, Fowke J, Dmochowski R. The Burden of Overactive Bladder on US Public Health. Curr Bladder Dysfunct Rep 2016; 11:813.

[25] Kobelt-Nguyen G, Johannesson M, Mattiasson A, Abrams P. Correlations between symptoms of urge incontinence and scores of a generic quality of life instrument (SF36) and health status measurements (EuroQoL) and between changes in symptoms and QoL scores (abstract). 27th Annual Meeting of the International Continence Society, Yokohama, Japan, September 23-7, 1997.

[26] Coyne K, Revicki D, Hunt T, et al. Psychometric validation of an overactive bladder symptom and health-related quality of life questionnaire: The OAB-q. Quality of Life Research 2002; 11: 563-574.

[27] Gu J, Restorick JM, Blank MA, et al. Vasoactive intestinal polypeptide in the normal and unstable bladder.Br J Urol 1983; 55:645647.

[28] Rechberger T, Kulik-Rechberger B, Miotła P, Wrobel A. The new era in the pharmacological treatment of overactive bladder (OAB): mirabegron-a new selective beta3 agonist. Ginekol Pol 2014; 85:214-219.

[29] Kinsey D, Pretorius S, Glover L, Alexander T. The psychological impact of overactive bladder: A systematic review. J Health Psychol 2014; 21:69-81. 
Incidence of Ambulatory Care Visits and Association with Comorbidities of Overactive Bladder in Taiwan

Citation: Hsin-Li Liu, Kai-Yu Tseng, Shu-Ching Chiu, Horng-Mo Lee \& Yueh-Chin Chung. Incidence of Ambulatory Care Visits and Association with Comorbidities of Overactive Bladder in Taiwan. ARC Journal of Urology. 2017; 2(4):1-7 doi: dx.doi.org/10.20431/2456-060X.0204001.

Copyright: (C) 2017 Authors. This is an open-access article distributed under the terms of the Creative Commons Attribution License, which permits unrestricted use, distribution, and reproduction in any medium, provided the original author and source are credited. 